\title{
Apontamentos sobre a encruzi- lhada como perspectiva crítica para as artes visuais
}

Notes about the crossroads as a critical perspective for the visual arts

Notas sobre la encrucijada como una perspectiva crítica para las artes visuales

\author{
Leandro (Napê) Rocha \\ Universidade do Estado do Rio de Janeiro \\ E-mail: rocha.Indr@gmail.com \\ ORCID: 0000-0001-6514-6041
}

RESUMO:

Este ensaio/experimento pretende estabelecer um diálogo com pesquisadores, curadores, artistas e demais pessoas interessadas nos saberes-fazeres das artes afro-diaspóricas a partir da fundamental contribuição da poetisa Leda Maria Martins e do princípio da encruzilhada. Esse exercício crítico aponta algumas ideias a respeito do trabalho no campo das artes visuais manuseando a noção de encruzilhada como princípio orientador e organizador das práticas nesse campo.

Palavras-chave: Encruzilhada. Exu. Artes Visuais. Crítica; Curadoria.

\section{ABSTRACT:}

This essay/experiment intends to establish a dialogue with researchers, curators, artists and other people interested in the knowledge of Afro-Diasporic arts based on the fundamental contribution of the poet Leda Maria Martins and the principle of crossroads. This critical exercise points out some ideas regarding work in the field of visual arts, handling the notion of crossroads as a guiding and organizing principle of practices in this field.

Keywords: Crossroads. Exu. Visual arts.; Criticism. Curatorship.

ROCHA, Leandro (Napê). Apontamentos sobre a encruzilhada como perspectiva crítica para as artes visuais. PÓS:Revista do Programa de Pós-graduação em Artes da EBA/UFMG. v. 11, n. 22, mai-ago. 2021 Disponível em < $\underline{\text { https://eba.ufmg.br/revistapos }>}$ 


\section{RESUMEN:}

Este ensayo/experimento tiene la intención de establecer un diálogo con investigadores, curadores, artistas y otras personas interesadas en el conocimiento de las artes afrodiaspóricas basado en la contribución fundamental de la poeta Leda Maria Martins y el principio de la encrucijada. Este ejercicio crítico señala algunas ideas sobre el trabajo en el campo de las artes visuales, manejando la noción de encrucijada como un principio rector y organizador de prácticas en este campo.

Palabras clave: Encrucijada. Exu. Artes visuales. Crítica. Curaduría.

Artigo enviado em: 19/07/2020 Artigo aprovado em: 06/04/2021

ROCHA, Leandro (Napê). Apontamentos sobre a encruzilhada como perspectiva crítica para as artes visuais. PÓS:Revista do Programa de Pós-graduação em Artes da EBA/UFMG. v. 11, n. 22, mai-ago. 2021 Disponível em < https://eba.ufmg.br/revistapos $>$ 


\section{Primeira esquina: a benção aos mais velhos}

Nas primeiras páginas do livro Afrografias da memória: o Reinado do Rosário no Jatobá (1997), a poetisa, ensaísta, congadeira, dramaturga e professora Leda Maria Martins narra os primeiros passos de uma caminhada por uma pesquisa a respeito das performances orais e corporais nas manifestações de origem banto em Minas Gerais, especificamente o Reinado do Rosário. Passagem importante é a que conta do momento decisivo na empreitada do trabalho no ano de 1993, quando é convocada por João Lopes, seu mais velho e capitão-mor no Reinado, a recontar a história do Reinado em um livro. João Lopes padecia de doença grave e, temendo cumprir sua passagem e levar consigo parte importante da história da Irmandade de Nossa Senhora do Rosário, encarrega à Leda Maria Martins a responsabilidade de registrar, interpretar e traduzir a rica tradição oral e ritual de sua comunidade. A teórica-congadeira havia sido, ainda criança, princesa conga da mesma congregação a qual João Lopes fora mestre. Apenas algum tempo depois da minha primeira leitura daquelas páginas foi que descobri que Leda Maria Martins é também rainha conga daquela irmandade. Veja, ela não foi apenas autorizada, mas convocada a dar conta de uma responsabilidade que importava não apenas à sua trajetória de pesquisa, mas também à manutenção e continuidade de um aspecto de grande valia para a cultura e comunidade da qual ela é oriunda.

\section{Segunda esquina: nós não navegamos sós}

Incorporando a sabedoria do povo Akan, que nos orienta a não temer retornar ao passado para recuperar algo que fora esquecido, Leda Maria Martins regressa à cosmologia africana julgando ser esse um caminho possível para a interpretação de um fenômeno cultural, que é, antes de tudo e apesar de seus cruzamentos, negro e de tradição banto, recuperando nas águas do Atlântico (como fizeram os negros com a imagem da santa) uma sabedoria necessária para significar essa experiência que é também da ordem do rito e do mito. Exu ensina à autora que, apesar das modalidades diversas de mortificação a que foram submetidos africanos e seus descendentes nos processos de captura, roubo e desumanização perpetrados pelos europeus e seus descendentes, foi possível fecundar, nessas terras, a possibilidade de reinvenção da vida, apesar das adversidades. Não foi de forma pacífica que as culturas negras nas Américas se constituíram como culturas de encruzilhada.

ROCHA, Leandro (Napê). Apontamentos sobre a encruzilhada como perspectiva crítica para as artes visuais. PÓS:Revista do Programa de Pós-graduação em Artes da EBA/UFMG. v. 11, n. 22, mai-ago. 2021 Disponível em < $\underline{\text { https://eba.ufmg.br/revistapos }>}$ 
Leda Maria Martins explica que as culturas africanas, mesmo dispersas, cruzaram suas tradições e memórias com os demais sistemas simbólicos com os quais se defrontaram, criando, inclusive, relações de aliança como é observável, por exemplo, na aproximação dos povos banto com as tradições indígenas originárias dessas terras.

Exu desejou ser explicado pela autora de forma a anunciar tanto suas próprias características quanto os elementos constitutivos do território que habita e comanda, em uma dinâmica em que forma e conteúdo não são dissociáveis, mas amalgamados. Exu, articulador e mantenedor do sistema dinâmico nagô, estabelece as conexões entre todas as fronteiras do(s) mundo(s), mediando todos os atos de criação e interpretação do conhecimento (a tradição diz que sem Exu não se faz nada, nem mesmo aquilo que conhecemos, descrevemos e experienciamos como arte). Em sua recusa às classificações limitantes, Exu nos permite fabular e inventá-lo de maneiras diversas, ao gosto de quem risca o ponto, não nos furtando, entretanto, de cairmos nos riscos de nossas próprias palavras, que não é apenas uma porção da realidade a qual ele domina, mas o que ele também é, por excelência. ${ }^{1}$ Trata-se de um jogo de sedução, na verdade. Desejamos Exu em todas as suas artimanhas.

\section{Terceira esquina: uma aparente contradição}

Ainda que o Reinado seja entendido pela autora e por seus próprios personagens-narradores como uma manifestação cultural de origem banto e, ao primeiro olhar, Exu possa ser interpretado unicamente como uma "divindade iorubana", devemos lembrar que: 1) as culturas das quais Leda Maria Martins elabora sua proposta de uma encruzilhada, e das quais somos descendentes, não operam na lógica da pureza, mas na aglutinação, seja em sua raiz, seja na diáspora. É a encruzilhada que as organiza, o que difere em absoluto das mentiras contadas pelos europeus, que insistem em aniquilar as particularidades entre os povos africanos e seus descendentes, transformando-nos em uma unidade quase amorfa, para, assim, aniquilar-nos por completo; 2) Exu rejeita classificações unívocas e, entre África e Brasil, também pôde se transmutar. Se duvida, pergunte ao povo da rua.

ROCHA, Leandro (Napê). Apontamentos sobre a encruzilhada como perspectiva crítica para as artes visuais. PÓS:Revista do Programa de Pós-graduação em Artes da EBA/UFMG. v. 11, n. 22, mai-ago. 2021 Disponível em < $\underline{\text { https://eba.ufmg.br/revistapos }>}$

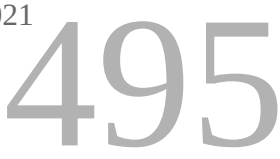




\section{Quarta esquina: a abertura do princípio da encruzilhada}

Para manusear como ferramenta analítico-metodológica, Leda Maria Martins organiza o princípio da encruzilhada em dois termos não excludentes, que introduzem e induzem para aberturas infinitas (como é a própria encruzilhada). Primeiro, a encruzilhada opera como princípio que oferece a possibilidade de leitura e interpretação dos trânsitos de produção de conhecimentos, de sistemas simbólicos e de diversas formas de experienciar e dar sentido ao mundo, que se confrontaram e organizaram aquilo que uma vez foram tidos como inaugurais, originários. A encruzilhada é uma lente através da qual podemos ler a realidade das culturas afro-diaspóricas. Segundo, a encruziIhada é o território onde essas trocas se estabelecem nos jogos de negociação entre os entes implicados nas relações de conflito e cruzamento. É descrita pela autora como um "lugar terceiro", pois sua premissa é a da criação, a da produção de uma outra coisa que não mais aquela que a inaugurou, mas que, ainda assim, pode ser identificada como sua descendente à medida em que a interpretamos através de sua própria gramática. Desenraizados e surrupiados de suas próprias imagens, a encruzilhada (Exu) permitiu que os africanos e seus descendentes pudessem assentar seus modos de vida nesse novo território. Veja bem, Leda Maria Martins de maneira nenhuma procura recontar o já desgastado mito das três raças na formação do território sociocultural brasileiro. Ao invés disso, destaca o protagonismo de Exu como valor civilizatório para a continuidade dos modos de vida de um povo em terras hostis.

\section{Quinta esquina: um jogo de sete peças}

A ideia de "jogo" é útil para a composição da imagem do território material/imaterial que é a encruzilhada. Ao dinamizar a encruzilhada, Exu propicia a instauração de um espaço de invenção, movimentação, descontinuidade e heterogeneidade, caracteres elementares para o estabelecimento de um conjunto de regras que ordenam a movimentação de um grupo e de suas interações (os circuitos das artes, por exemplo). O jogo se faz a partir da abertura e da disponibilidade para a troca, e também da emergência de vozes múltiplas, corpos, narrativas, trajetórias e, como não poderia deixar de ser, de diferentes intenções orientadas para determinados fins. No trabalho No antiquário eu negociei o tempo (2018), Castiel Vitorino Brasileiro narra um caso de disputa e negociação com o dono de um antiquário que visitou em ocasião de uma residência artística na zona portuária de Santos, São Paulo. Castiel conta que ao questionar o branco dono do antiquário (que

ROCHA, Leandro (Napê). Apontamentos sobre a encruzilhada como perspectiva crítica para as artes visuais. PÓS:Revista do Programa de Pós-graduação em Artes da EBA/UFMG. v. 11, n. 22, mai-ago. 2021

Disponível em < $\underline{\text { https://eba.ufmg.br/revistapos }>}$

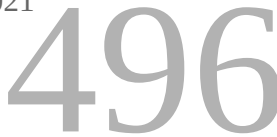


na sua posição é também um curador) a respeito de um conjunto de máscaras que ela encontrara no acervo do local, o antiquarista atribui aos objetos uma origem transatlântica: as máscaras seriam antiguidades originárias do continente africano (sem especificação de qual região, cultura, povo ou período pertenceriam). Cismada, a artista inquire novamente e recebe uma resposta remodelada: as máscaras teriam sido feitas por uma escultora de origem africana em terras brasileiras (nesse caso, a autoria conservaria sua suposta originalidade?). Castiel não se convence e interroga novamente. Dessa vez, o dono do antiquário, finalmente, responde que os objetos eram frutos de uma oficina que ministrou para crianças ali mesmo. Na medida em que o antiquarista atribui primeiramente os objetos a um território distante, confere também uma temporalidade outra, passada, deslocada, na medida em que a "África" a qual se refere de maneira genérica não é contemporânea daquele que atravessa as mercadorias. Em uma espécie de coreografia, Castiel e o antiquarista negociam e, por isso, jogam, cada uma com suas intenções, uma vez que barganham não só o território em que os objetos estão circunscritos, mas também sua narrativa, sua localização no tempo e legitimidade como "objeto originário" e original, que pode ou não participar do campo da arte, além, é claro, do valor financeiro atribuído, que decresce a medida em que o objeto se aproxima do nosso tempo, do nosso território e da artista que, ao final, adquire as peças. O curador de inspiração cubista, em sua imaginação, pilha as "máscaras africanas" que, na ação de Castiel, são repatriadas e passam a compor um outro tipo de acervo e imagem, que não é propriamente "verdadeira" (como se fosse impassível de questionamentos), mas que respondem aos desejos de recontar uma história que as coloca no tempo presente e as livra de atribuições colonizadoras.

\section{Sexta esquina: a produção de imagens duais/dupla face}

O exercício crítico, isso que estamos fazendo, é sempre a produção de um transbordamento em relação àquilo que se quer observar/ler no conjunto das coisas do mundo que optamos trazer para o interior do que negociamos coletivamente como arte, mesmo que o objeto não tenha sido criado para esse fim. Se lermos esse objeto através da encruzilhada é possível que estejamos aptos a observar o que Leda Maria Martins chama de "imagens duais" ou de "dupla-face", produzidas através da aproximação dos entes/sistemas que se encostam de modo a criar um terceiro corpo/ fenômeno. A crítica é também esse corpo terceiro, criado a partir do nosso encostamento em

ROCHA, Leandro (Napê). Apontamentos sobre a encruzilhada como perspectiva crítica para as artes visuais. PÓS:Revista do Programa de Pós-graduação em Artes da EBA/UFMG. v. 11, n. 22, mai-ago. 2021 Disponível em < $\underline{\text { https://eba.ufmg.br/revistapos }>}$ 
relação ao que desejamos interpretar, sem submetê-la ao seu objeto. Olhar através da dupla-face possibilita enxergar as contradições e desvios no interior daquilo que se está observando, sem tomá-lo como coisa acabada, nem mesmo o resultado da crítica.

Aqui vai mais um causo: em 1968 (só 80 anos depois da falsa abolição da escravatura), o crítico Clarival do Prado Valladares, apesar de identificar uma "modesta" presença de artistas negros no circuito de arte daquela época, atribuiu essa lacuna mais às condições socioeconômicas dos artistas do que às discriminações de ordem racial (mesmo que concorde que estão os pretos entre os mais empobrecidos), e foi categórico ao afirmar que aos artistas negros importava a presença de um "lastro cultural africano, ou afro-brasileiro" (VALLADARES, 1968, p. 100) em suas obras que deveriam se expressar "como cultura negra" (VALLADARES, 1968, p. 104). Segundo sua leitura, alguns artistas estavam mais alinhados a uma estética cosmopolita do que a um suposto compromisso com a cultura negra, mas veja o caso do pintor Arthur Timotheo da Costa, quem o crítico considera um artista capturado pelos interesses estilísticos da elite de gosto forâneo. O pintor que, apesar de livre, nasceu ainda sob o regime escravocrata, formou-se na então Escola Nacional de Belas Artes, onde recebeu educação formal de acordo com o estilo canônico europeu, como não poderia ser diferente. Com seu notável talento e domínio da técnica reconhecido pelos seus pares, Arthur Timotheo da Costa recebeu como prêmio uma viagem a Paris por sua participação em uma das edições da Exposição Geral de Belas Artes em 1907 (apenas 19 anos depois da assinatura da Lei Áurea), onde pôde estudar e trabalhar por aproximadamente dois anos. O pintor incorporou uma ginga necessária para negociar com o cânone, com sua formação acadêmica, com seus pares, com todos os obstáculos que cercavam a vida de uma pessoa negra naquele período da história, e pôde, ao menos por um curto período de tempo e até um certo limite, autodeterminar o sentido e a direção de sua biografia. Ele também tratou de se inscrever na história da arte autorretratando-se como pintor, manuseando pincéis e paletas, e também direcionando a atenção do seu trabalho para outras pessoas negras, em sua diversidade, em variados estudos. Infelizmente sua morte foi prematura e solitária no Hospício dos Alienados no Rio de Janeiro, aos 40 anos de idade, o que não significa, de forma alguma, esquecimento (a verdadeira morte que impede a transição para uma experiência de outra ordem, a da ancestralidade e que tanto nos é cara), ao menos por parte daqueles realmente comprometidos com uma revisão crítica da história da arte brasileira. Repare bem que não há, na narração desse caso, qualquer defesa a uma suposta meritocracia ou uma

ROCHA, Leandro (Napê). Apontamentos sobre a encruzilhada como perspectiva crítica para as artes visuais. PÓS:Revista do Programa de Pós-graduação em Artes da EBA/UFMG. v. 11, n. 22, mai-ago. 2021 Disponível em < $\underline{\text { https://eba.ufmg.br/revistapos }}>$ 
supervalorização de um percurso individual, como se, excedendo à regra, a trajetória do pintor inviabilizasse a crítica em torno das dificuldades de legitimação do trabalho de artistas negras no circuito e na história da arte. Fosse esse o caso, se bastasse unicamente o mérito do trabalho do artista, Arthur Timotheo da Costa teria reconhecida a sua contribuição nos momentos que antecederam ao modernismo tão celebrado no Brasil, ou teríamos registrado ao menos uma exposição posterior a sua morte, que reunisse o conjunto de sua obra, como aponta a pesquisadora e artista Renata Felinto dos Santos (2019).

\section{Sétima esquina: gira aberta no espaço expositivo}

Em muitas ocasiões, adentrar uma exposição pode ser descrito quase como uma experiência de súbito deslocamento geográfico, seja pela brancura dos sujeitos que visitam, dos que trabalham ou pelos objetos que compõe o espaço. A Presença negra, ${ }^{2}$ ação coletiva de artistas negros, proposta por Moisés Patrício e Peter de Brito, levou um grupo para ocupar salas de exposição como observadores-propositores, na medida em que a presença negra coletiva como público propunha e efetivava uma transformação no espaço. Novamente, estamos nos dispondo não apenas a tramar individualmente com nossos pares, cujos interesses são próximos (mas ainda o fazemos, porque é preciso estratégia), mas também a negociar com grupos, instituições, programas e projetos curatoriais. Quanto a isso, uma curadoria que emerge da/na encruzilhada traduz uma tentativa primeira de amálgama de multiplicidades a serem lidas, umas através das outras, em uma lógica de circularidade, em que a noção de centro e periferia se dilui para dar lugar a uma conversa coletiva entre os entes que coabitam o território uma vez criado. A produção de uma narrativa curatorial aponta para a instauração de um espaço de inventividade coletiva, e a encruzilhada possibilita que saberes, estéticas, formas e experiências afro-diaspóricas sejam privilegiadas para dar conta de uma experiência de corpo inteiro e não apenas de olhos em direção a um objeto centralizado. A lógica é a de uma gira aberta. Essa é sempre uma produção coletiva que pretende desvelar o campo da arte como espaço de suposta neutralidade, assepsia e universalidade, produzindo sempre, nas fissuras criadas, brotamentos outros. Talvez seja preciso desmantelar os modelos e lógicas espaciais com os quais estamos acostumados, reposicionar e reenquadrar objetos e também os sujeitos que fazem parte das dinâmicas de produção de arte.

ROCHA, Leandro (Napê). Apontamentos sobre a encruzilhada como perspectiva crítica para as artes visuais. PÓS:Revista do Programa de Pós-graduação em Artes da EBA/UFMG. v. 11, n. 22, mai-ago. 2021

Disponível em < $\underline{\text { https://eba.ufmg.br/revistapos }>}$

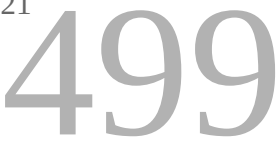




\section{Oitava esquina: a pedra lançada hoje é a pedra fundamental}

A encruzilhada é o território móvel de criação que permite a expressão de uma ancestralidade viva, ritualizada, organizada nos tempos do presente, e que enseja a elaboração de futuros em comum. De volta à sabedoria expressa pelo Sankofa, não devemos nos constranger em recuperar o que já foi articulado e, de alguma maneira, temos de nos responsabilizar em retomar, citar, referenciar, discutir, publicizar e compartilhar as contribuições de pensadores, artistas e criadores negros, que, assim como Leda Maria Martins, fundamentam o debate do que tem sido discutido como "epistemologias das encruzilhadas", que articulam em um só tempo, uma leitura analítica e uma experiência incorporada com o que se pretende tecer em termos de diálogo coletivo. Essa discussão tem sido amplamente difundida e feita pelos mais diversos sujeitos com todas suas complexidades de repertório e trajetórias, como deve ser. Pensar e grafar no corpo a encruzilhada se mostra como um gesto mais do que necessário em um contexto cujas estratégias de invenção de formas extraordinárias de vida tornam-se um imperativo para espantar das cidades a Morte, que nos racializa e intenta submeter-nos ao coma irreversível. A proposição de Leda Maria Martins como provocação para uma abertura de possibilidades serve-nos não apenas como ferramenta teórico-metodológica, mas de alento para a produção de singularidades e de quilombos que têm a encruzilhada como território de encontro e local de expansão. Que seja a energia desestabilizadora-ordenadora e criativa da encruzilhada a propulsora para a insurgência de uma outra história dos objetos de arte, qual seja, a que artistas negros não estejam espremidos na periferia da história e da crítica, mas sejam compreendidos em suas multiplicidades e singularidades como participantes, articuladores e estrategistas no jogo do mundo da arte. Ademais, a história da arte não é apenas a história dos seus objetos, mas, sobretudo, a história dos seus autores/criadores. Como ensinou Odé Kayodè (lyá Stella de Oxóssi), as encruzilhadas são uma suspensão no tempo, lugares de passagem de um estado a outro, e Exu, como bússola, nos orienta e nos inspira, permitindo elaborar quais caminhos seguir (SANTOS, 2010).

ROCHA, Leandro (Napê). Apontamentos sobre a encruzilhada como perspectiva crítica para as artes visuais. PÓS:Revista do Programa de Pós-graduação em Artes da EBA/UFMG. v. 11, n. 22, mai-ago. 2021

Disponível em < $\underline{\text { https://eba.ufmg.br/revistapos }}>$ 


\section{REFERÊNCIAS}

BRASILEIRO, Castiel Vitorino. No antiquário eu negociei o tempo. 2018. Disponível em: <https://castielvitorinobrasileiro.com/_foto_antiq>. Acesso em: 19 jul. 2020.

flor do nascimento, wanderson. Prefácio: exuzinhando a memória. In: SILVA, Cidinha da. Um exu em Nova York. Rio de Janeiro: Pallas, 2018.

MARTINS, Leda Maria. Afrografias da memória: o Reinado do Rosário no Jatobá. Belo Horizonte: Mazza, 1997.

SANTOS, Maria Stella de Azevedo. Balaio de Ideias: Na encruzilhada da vida. Jornal A Tarde, Salvador, 31 jul. 2010. Disponível em: <http://mundoafro.atarde.uol.com.br/balaio-de-ideias-naencruzilhada-da-vida/>. Acesso em: 11 jul. 2020.

SANTOS, Renata Aparecida Felinto dos. A pálida História das Artes Visuais no Brasil: onde estamos negras e negros?. Revista GEARTE, Porto Alegre, v. 6, n. 2, jul. 2019. Disponível em: <https://seer.ufrgs.br/gearte/article/view/94288/53218>. Acesso em: 11 jul. 2020.

VALLADARES, Clarival do Prado. O negro brasileiro nas artes plásticas. Cadernos Brasileiros, Rio de Janeiro, v. X, n. 47, p. 97-109, maio/jun. 1968.

ROCHA, Leandro (Napê). Apontamentos sobre a encruzilhada como perspectiva crítica para as artes visuais. PÓS:Revista do Programa de Pós-graduação em Artes da EBA/UFMG. v. 11, n. 22, mai-ago. 2021

Disponível em < $\underline{\text { https://eba.ufmg.br/revistapos }>}$ 


\section{NOTAS}

1 No prefácio do livro Um Exu em Nova York (2018, p. 9), de Cidinha da Silva, Tata ria nkisi Nkosi Nambá, o pesquisador wanderson flor do nascimento diz: “Exu anda com as palavras, anda nas palavras, anda pelas palavras, anda as palavras. Por viver (n)as palavras, como vive (n)as ruas, (n)as encruzilhadas, (n)os caminhos, Exu as tem como ferramenta para fazer mundos, encontros, memória".

2 Para saber mais sobre a Presença negra, ver <https://artebrasileiros.com.br/arte/paredes-brancaspresenca-negra/>. Acesso em: 19 jul. 2020. 